\title{
The nest-holding grass goby (Zosterisessor ophiocephalus) male adjusts the spawning activity in relation to parasitic nest intrusions
}

\author{
Stefano Malavasi • Marco Lugli • \\ Patrizia Torricelli • Danilo Mainardi
}

Received: 2 April 2007 / Accepted: 30 July 2007 / Published online: 18 October 2007

(C) Springer Science + Business Media B.V. 2007

\begin{abstract}
This study examines the temporal pattern of spawning behavior by the territorial (i.e. nest-holding) grass goby male, Zosterisessor ophiocephalus, in response to sneak intrusions by the small parasitic male under controlled laboratory conditions. The spawning activity of the territorial male consists of a sequence of upside-down movements on the ceiling of the nest accompanied by undulations of the body and sperm release. Five pairs of one territorial male and one parasitic male, each kept inside a large tank provided with an artificial buried nest (always occupied by the territorial male) and one small tunnel-shaped shelter (always occupied by the small male), were observed during one-female spawning taking place in the innermost part of the nest (i.e. the nest chamber). During the spawning, the presence of the small male nearby the nest openings elicited aggressive behavior and increased nest patrolling by the territorial male. In one spawn the small male never attempted to enter the nest. In four spawns the small male entered one to three times the nest chamber (sneaks), staying there from 2 to
\end{abstract}

S. Malavasi $(\bowtie) \cdot$ P. Torricelli $\cdot$ D. Mainardi

Dipartimento di Scienze Ambientali,

Università Ca' Foscari di Venezia,

Castello 2737/b,

30122 Venezia, Italy

e-mail:mala@unive.it

M. Lugli

Dipartimento di Biologia Evolutiva e Funzionale,

Università di Parma, Parco area delle Scienze,

43100 Parma, Italy
203 s until the large male chased him away. The temporal patterning of the spawning activity by the territorial male (bouts of upside-down, U-D), and its changes following a sneak by the small male, were investigated using bout analysis and correlative tests. Results showed the length of bouts U-D did not change significantly after a sneak intrusion. whereas gap length (i.e. the period between subsequent bouts U-D) decreased significantly after each sneak intrusion. The mean duty cycle of bouts U-D tended to be positively correlated to the number of sneaker intrusions of each replicate. Results are discussed in the light of current knowledge on sperm competition among externally fertilizing teleosts.

Keywords Parasitic behavior.

Sperm competition risk $\cdot$ Alternative tactics

\section{Introduction}

External fertilization, the most common reproductive mode in teleost fish, requires both the simultaneous release of spermatozoa and ova in the water and the proximity of the sexual partners (Marconato et al. 1996; Kemadjou Nijwa et al. 2004). It also enables two or more males to spawn simultaneously, thereby allowing direct sperm competition and, hence, the evolution of alternative mating tactics. The risk of sperm competition may lead to the evolution of several behavioral adaptations enhancing the fertilization 
efficiency of spermatozoa (from simple increase of sperm production to changes in timing of sperm release, sperm traits and proximity of females to males; Stoltz and Neff 2006). Knowledge of the dynamics of sperm release and the patterns of sperm release behavior is therefore of paramount importance to fully understand the male strategies aimed at increasing the male fertilization success.

The family Gobiidae includes many territorial species with male alternative reproductive strategies (Cole 1982; Magnhagen 1992; Mazzoldi et al. 2000; Malavasi et al. 2001). The sperm release behavior of the territoryowner male goby typically consists of several upsidedown movements performed on the ceiling of a nest during courtship and egg-spawning while the female is nearby, or inside, the nest cavity (Marconato et al.1996; Ota et al.1996). While turned upside-down, the male rubs its genital papilla against the ceiling of the nest cavity and releases sperm trails from which spermatozoa are released directly into the water for several minutes after spawning. Such male upside-down movements are found in all stages of the reproductive behavior, i.e. they occur before, during and after the egg-laying phase of the breeding cycle.

The study of the goby spawning behavior has been conducted primarily on one species, the grass goby Zosterisessor ophiocephalus (Ota et al. 1996; Scaggiante et al. 1999; Mazzoldi et al. 2000; Torricelli et al. 2000). The large grass goby male adopts the territorial tactic, i.e., it digs and defend burrows under the seagrass rhizomes that are used by females as spawning substrate. Such males are exposed to the risk of sneaking by small, younger males (Scaggiante et al. 1999; Mazzoldi et al. 2000; Torricelli et al. 2000). In the field, small males are often found in the nests occupied by one large-size male (Mazzoldi et al. 2000; Torricelli et al. 2000; Malavasi et al. 2002). Considering the high risk of sperm competition because of the presence of small males in the nests, the presence of behavioural adaptations aimed at increasing the fertilization success of the territorial male are expected in this species.

The present study examines the temporal pattern of bouts of upside down movements performed by the nest-holding grass goby male in the nest, and possible changes of mean bout length and duty-cycle following the sneaking intrusions by the small parasitic male. Results are interpreted within the context of current knowledge on the strategies adopted by parental males to counter the risk of sperm competition.

\section{Materials and methods}

\section{Experimental set-up}

Fish were caught in the Venice lagoon with the aid of fyke nets (fixed gear used by local fishermen) at the beginning of the breeding season (March). Five largesized, fin rays elongated males (range: 180-210 mm, total length [t.l.]) were paired with 5 small-sized males lacking fin rays elongation (range: $110-142 \mathrm{~mm}$, t.l.) and each pair of one large male and one small male was singly put into a large experimental tank (500 1 capacity). Each tank was provided with a layer of $50 \mathrm{~cm}$ of fine gravel and one artificial nest buried into the gravel (Fig. 1). The nest consisted of one chamber, i.e., a half of a rectangular plastic box $(25 \times 5 \times 18 \mathrm{~cm})$, and two side entrances, i.e., two longitudinal halves of a cylindrical tube (length: $15 \mathrm{~cm}$, diameter: $6 \mathrm{~cm}$ ) placed at both ends of the box, one on each side. The half-box simulated the main, and often the only, chamber used by the male Z. ophiocephalus as spawning site in the field (Ota et al. 1996), whereas the half-cylinders simulated the two nest entrances of the hypothetical reproductive nest in the field. The whole construction was placed against the inner of the aquarium front wall, just below the bottom surface as shown in Fig. 1. In this manner, an external observer could see the inside of the artificial nest through the transparent wall. A large portion of the front wall below the bottom surface was covered with an external, large rectangular box (i.e., the dark-room box, Fig. 1), opened on the side facing the aquarium wall (Fig. 1). The dark-room box obscured the inner of the artificial nest so as to simulate the condition of darkness likely present inside the reproductive nest in the field. Two TV cameras, each connected to a separate VHS video-recording system, were used to record the behavioral sequences. One TV camera (Hitachi VM 4400E) monitored the bottom of the tank, whereas the other camera (a miniature, infrared video-camera) was placed inside the dark-room box and monitored the inside of the nest chamber.

This system allowed the simultaneous recording of behavioral events taking place inside and outside the artificial nest (Fig. 1). Sound production in the nest was monitored by connecting the video-system with a small-size hydrophone (B and $\mathrm{K}$ miniature hydrophone, type 8103) positioned inside the nest chamber as shown in Fig. 1. The hydrophone was connected to 

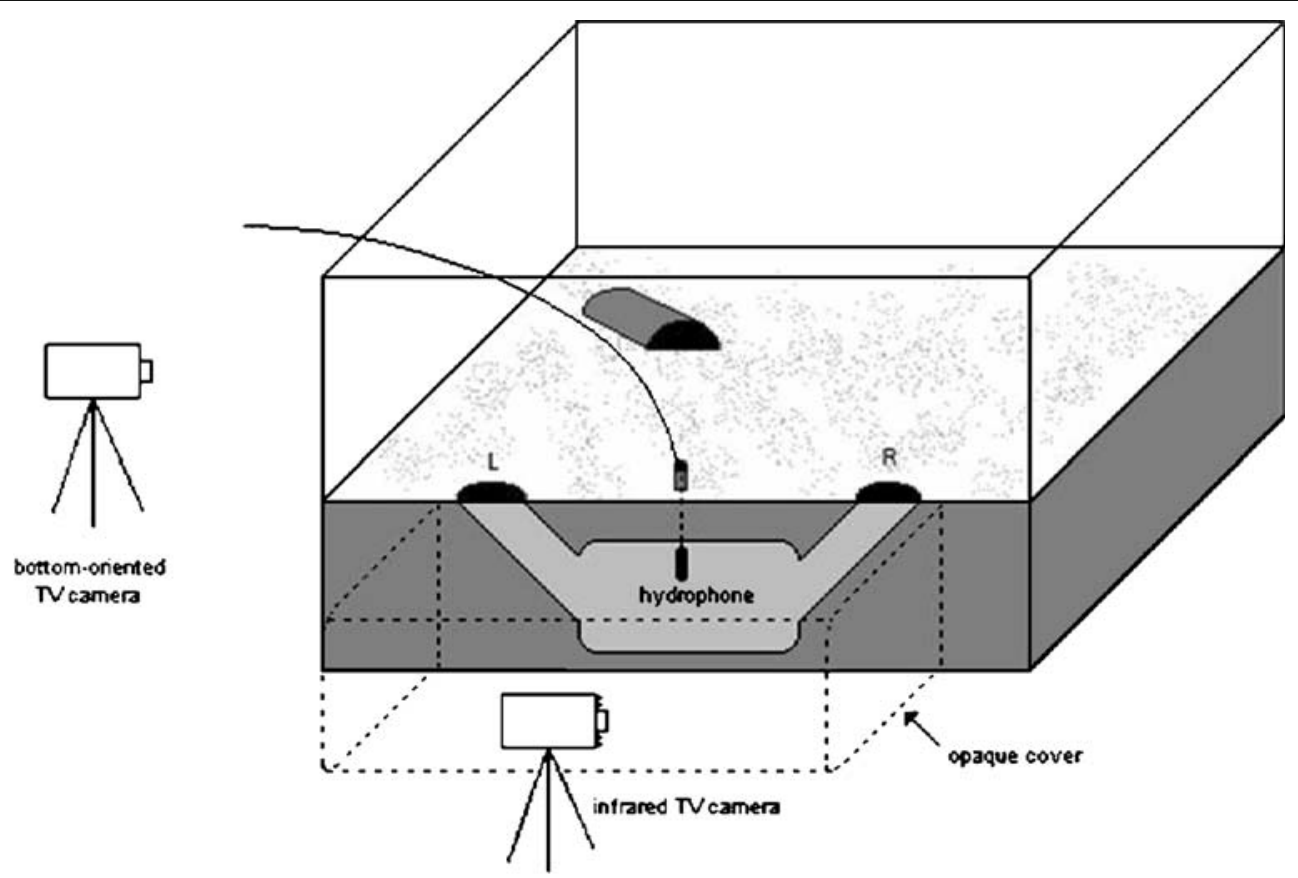

Fig. 1 Experimental set-up for the study of the behavioral interactions between the large and small male of the grass goby, Zosterisessor ophiocephalus. The main chamber of the artificial nest, and the two entrance tubes opening at the bottom surface, are shown (light gray). The whole nest structure, buried into a thick layer of coarse gravel (dark gray), was arranged against the front wall of the aquarium in such a way that the inside of the nest was fully visible to an external viewer. The dark room-

a low-noise, pre-amplifier (B and $\mathrm{K}$ type 2626). Water salinity was kept between 30 and $35 \%$; ambient temperature and photoperiod followed the natural conditions $\left(20-21^{\circ} \mathrm{C}\right.$, light: $\left.8 \mathrm{~h}\right)$.

\section{Experimental procedure}

After the pair was introduced in the tank, the behavioral interactions between the two males were observed daily, for a period of $30 \mathrm{~min}$ approximately, for 1 week, also noting which male occupied the artificial nest. In all the 5 pairs observed, the large male always settled into the nest, whereas the small male occupied the small, tunnelshaped shelter on the bottom. At the end of the first week of residency of the pair into the tank, a ripe female was introduced into the tank. When spawning begun (always into the artificial nest occupied by the large male) the video-acoustic system was switched on, and the behavior of the fishes in the tank was recorded continuously for $3.5 \mathrm{~h}$, a period sufficient for the complete recording of the sneaking activity of the small box (dotted outline) was placed against the front wall to darken the inside of the nest (see Materials and methods for details). An infrared TV camera, equipped with six infrared leds, was placed inside the box for the video-recording of the behavior of fishes inside the nest. An additional TV camera was used to record the behavior of fishes on the bottom. The tunnel-shaped plastic shelter on the bottom, always occupied by the small male, was placed far from the two nest entrances

male (the activity of the sneaker male $Z$. ophiocephalus ends well before the completion of egg-spawning, which may take 4-6 h in this species; Ota et al. 1996). If the female did not begin spawning by $30 \mathrm{~min}$ since her introduction in the tank, she was replaced by another one. No effort was made to quantify the amount of sperm released by the male during the upside-down movements, e.g. by attaching slides or transparent sheets to the ceiling of the nest chamber to collect sperm trail (Ota et al. 1996; Scaggiante et al. 2005), as these manipulations would have caused disruption of the ongoing behavioral interactions taking place into the complex structure of the artificial nest. The observation of the rubbing of the genital papilla against the substrate while the male was turned upside, made possible by the high resolution of the infra-red TV camera, was taken as indirect proof of sperm release (see Introduction). Furthermore, microscope examination of a few samples of water, collected with a long micropipette inserted into the nest chamber through one of the two entrances during two spawns 
$(2,4)$, confirmed the presence of release of spermatozoa during oviposition.

Analysis of behavioral sequences

The analysis focused on behaviors performed by the small and large male inside the nest chamber. A preliminary inspection of videotapes showed that the interaction between the two males consisted of several behavioral activities, e.g. the patrolling behavior of the large male, the waiting behavior of the small male at the nest entrance or attacks and aggressive sounds directed towards the small male by the larger male. These behaviors were of little relevance to the purposes of the present investigation, as only the activity of Upsidedown (UD) of the two males was measured and examined quantitatively (see below). Considering the behaviours shown by the two males, the larger male was defined as "nest-holding male", while the small male as "parasitic male".

In four replicates (1-4) the parasitic male performed repeated sneaking attempts at the two nest openings, and entered the nest chamber one, or more, times during the ongoing spawning. In one replicate (5) the parasitic male stayed almost all the time in his shelter, and did not perform any sneaking attempt. In replicates with an active parasitic male the behavioral sequence was analyzed from the beginning of oviposition (the start of the behavioural record) until the parasitic male was no longer active. All these replicates, therefore, included an initial phase without sneaking activity (latency, i.e., period of time from the beginning of the record to the small male approaching one of the two nest openings for the first time), followed by the sneaking phase, measured as the total time of the record minus the latency, i.e., the sneaking period. Only for replicate 5, the behavioral sequence of the large male was analyzed from the beginning of oviposition, for a period of $3 \mathrm{~h}$ and $20 \mathrm{~min}$.

The five behavioral sequences were analyzed with the aid of a software package developed by one of the authors (ML), focusing on the UD activity of the large male. The sequence of bouts UD and gaps UD were determined for each replicate. The duration of each bout UD was measured from the time the male turns upsidedown to the time he resumes the normal posture, whereas the length of a gap UD was the time separating two consecutive bouts UD (Fagen and Young 1978; Haccou and Meelis 1992). The third variable of the spawning activity of the nest-holding male, the dutycycle of UD, combined bout length and the gap length measurements as follow:

$\mathrm{B}_{i} /\left(\mathrm{B}_{i}+\mathrm{G}_{i}\right) \times 100$,

$B_{i}$ being the duration of the $i$ th bout UD of the sequence, $G_{i}$ the length of the gap between the $i$ th bout UD and the $i$ th +1 bout UD. This index varied from nearly 0 to nearly $100 \%$ : the longer the bout UD relatively to the length of the following gap, the higher the index. The duty-cycle of UD, therefore, measures the proportion of time spent by the nest-holding male turned upside-down in a given position along the behavioral sequence.

Analysis of data and statistical procedures

Mean values of the three variables of the spawning activity of the large male (i.e. length of bouts UD, gap length and duty-cycle) were compared among the five replicates with the non-parametric ANOVA test (Siegel and Castellan 1992). For each variable, a post-hoc comparison between the mean value of each spawn with active sneaker and that of spawn 5 (no sneaking activity) acting as control treatment was carried out using the Kruskal-Wallis method for multiple comparisons (Siegel and Castellan 1992). The use of parametric ANOVA was not attempted because the assumption of normality of data was not generally met and, furthermore, in a number of cases the lack of normality persisted also after transformations of data (Sokal and Rohlf 1995). Temporal variations in the spawning activity of the nest-holding male were examined by computing the percentage of time spent upside-down by the large male within subsequent 5-min time intervals of the record and plotting the percentage values over time. In addition, the occurrence of each nest entering event by the small male was marked on the time axis. Since the five replicates differed for the total time of interaction, the number of time intervals of each record differed accordingly. The presence of a significant relationship of the mean duty-cycle with the number of nest entering events by the small male was tested with the Pearson product-moment correlation test using the correction for small samples (Sokal and Rohlf 1995). The occurrence of short-term changes in the mean length of bouts UD, gaps UD, and in the value of the duty-cycle, was examined on cumulative bout length 
plots (Haccou and Meelis 1992). The number and position of most significant points of change in bout/ gap duration along the sequence of bouts UD was determined using the non-parametric, distributionfree, Multiple Change Point Test (Haccou and Meelis 1992). The procedure consists of determining the maximum value of the test statistic (the KruskalWallis $K_{\mathrm{m}}$ ) for all possible places of the $N$ change points along the bout sequence ( $N=1,2$ and 3$)$, and testing in succession the presence of 3 change points against 2 change points, then 2 against 1 , and finally 1 against no change point. The procedure is stopped as soon as the difference is significant. Finally, the position of the significant change point/s in the sequence of bouts is noted. The position of each change point in the bout sequence, and that of each nest entering event by the small male, were plotted on the cumulative bout/gap length curves to seek for possible cause-effect relationships between the behavior of the two males. Similarly, the values of the duty-cycle were calculated and plotted in relation to the sequence number of the bout UD to detect local changes of intensity of the spawning activity of the nest-holding male. To minimize the masking effect of local random fluctuations of the duty-cycle, the values were smoothed using the method of the moving averages (see Results for details).

\section{Results}

Description of the parasitic male behavior

No sneaking-related activity by the parasitic male was performed during the courtship phase and the early period of the spawning phase. In the four replicates with an active parasitic male, the small male left the shelter and approached the artificial nest for the first time after 25-70 min (latency) from the onset of spawning. The total number of nest-entering attempts varied from 2 to 23 over the four replicate. Most attempts were not followed by the actual entering of the small male into the nest chamber (sneaking). The number of sneak intrusions amounted to 9 and varied from 1 to 3 per replicate (Fig. 2). The duration was remarkably variable (2-203 s, $n=9)$. In three cases (each on a separate replicate), the parasitic male turned upside-down and performed fertilizing movements by rubbing its genital papilla against the substrate for 30 ,
50 and $30 \mathrm{~s}$ (spawns 1, 3 and 4, respectively). All sneak intrusions ended with an attack by the large male toward the small male. After a period from 78 to $120 \mathrm{~min}(n=4)$, the small male lost any interest in the ongoing spawning and retreated permanently into his shelter. In replicate 5 the small male did not perform any parasitic behavior, spending most of the time in his shelter.

Behavioral responses of the nest-holding male to the presence of the parasitic male in the nest chamber

In all replicates, the amount of time spent upsidedown by the large male rested generally below $20 \%$ of the time interval (Fig. 2). Eight peaks in UD activity (i.e. percentage of time UD above $20 \%$ ) were observed: one occurring during latency (Fig. 2, replicate 1) and the others occurring during the Sneaking period always after a sneak intrusion (Fig. 2). All peaks were similarly characterized by an increase of UD activity from below $10 \%$ to a peak between $25-50 \%$, attained after $10-15 \mathrm{~min}$ from the sneak intrusion, followed by a decrease to the levels observed before intrusion. A complete cycle of variation of UD activity following a sneak intrusion lasted about 20-25 min (i.e. 4-5 time intervals on the plot of Fig. 2, shaded peaks).

A descriptive statistic of bouts and gaps of upsidedown of the five replicates is reported in Table 1. The mean length of bouts UD did not differ significantly among spawns (Kruskal-Wallis test: $t=4.8, n=231$; NS), whereas highly significant differences were found in mean gap length $(t=31.6, n=231, p<0.001)$ and mean duty-cycle of bouts UD $(t=21.5, p<0.001$, $n=231$ ). Results of the post-hoc comparisons showed the mean gap length and mean duty-cycle were significantly higher $(p<0.05)$ in three replicates with active sneaker (1, 3 and 4$)$ as compared to replicate 5, whereas the mean value of the same variables did not differ statistically between replicates 2 and 5 . It should be noted, however, that only one nest sneaking occurred in replicate 2 . Indeed, the mean value of the duty-cycle correlated positively and significantly with number of sneak intrusions of the replicate $(r=0.911$, $t=3.92, n=5, p<0.05$; Fig. 3 ).

The visual inspection of the cumulative bout length plots for UD (Fig. 4) showed no apparent change in mean bout length (indicated by a sudden change of slope on the cumulative plot) in the five replicates. 

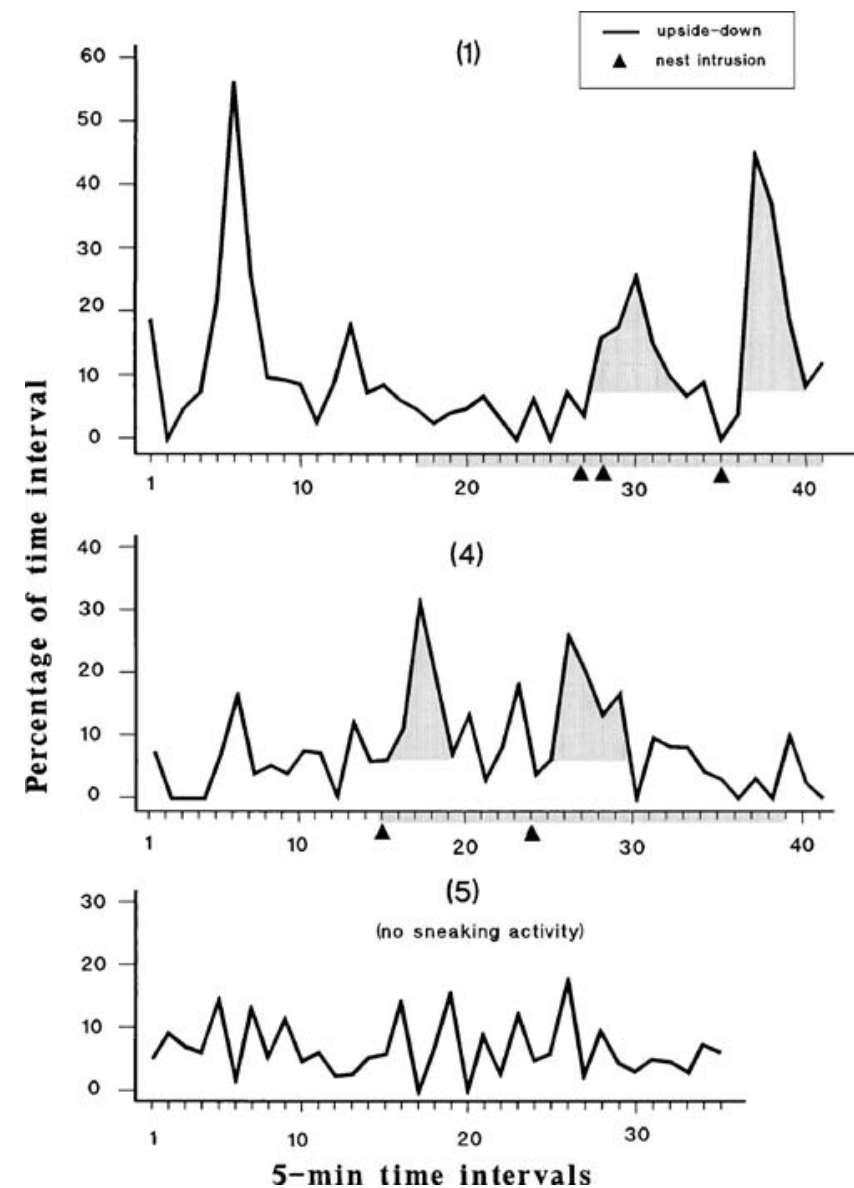

Fig. 2 Frequency of upside-down (expressed as percentage of time spent in the activity within 5 min intervals), from the beginning of egg-spawning and for the whole duration of the sneaking period (gray bar below the $X$-axis) in two replicates $(1,4)$ taken as an example, and during the replicate without

sneaking activity (5). The time occurrence of each nest intrusion by the parasitic male is indicated with a triangle below the $X$-axis. Notice the peak of activity of upside-down (shaded areas) following each nest intrusion

Table 1 Descriptive statistic of bouts and gaps of upside-down (UD) during the sneaking period of replicates $1,2,3$ and 4, and for the total time of replicate 5 (no sneaking activity)

\begin{tabular}{|c|c|c|c|c|c|c|}
\hline Replicates & $\begin{array}{l}\text { Percentage of time } \\
\text { UD }(\Sigma U D / S \times \\
100, \%)\end{array}$ & $\begin{array}{l}\text { No. of bouts } \\
\text { UD } N\end{array}$ & $\begin{array}{l}\text { Bout frequency } \\
(\Sigma U D / S \times 60 \text {, } \\
\text { bouts } / \mathrm{min})\end{array}$ & $\begin{array}{l}\text { Mean bout length } \\
\text { [range] }(\Sigma \mathrm{UD} / N, \mathrm{sec})\end{array}$ & $\begin{array}{l}\text { Mean gap length } \\
\text { [range] }(\Sigma \mathrm{GAP} / N, \mathrm{~s})\end{array}$ & $\begin{array}{l}\text { Duty-cycle } \\
\text { [range] }(\%)^{\mathrm{a}}\end{array}$ \\
\hline 1 & 11.0 & 51 & 0.41 & $16.0[4-66]$ & $133[2-548]$ & $21.8[0.9-89.6]$ \\
\hline 2 & 5.6 & 21 & 0.20 & $16.4[4-30]$ & $262[6-1085]$ & $14.0[1.9-77.8]$ \\
\hline 3 & 10.7 & 54 & 0.45 & $14.4[3-50]$ & 121 [4-419] & $20.4[2.0-91.4]$ \\
\hline 4 & 10.0 & 53 & 0.42 & $14.4[2-50]$ & $128[8-711]$ & $16.2[1.3-76.0]$ \\
\hline $\begin{array}{l}5 \text { (no } \\
\text { sneaking } \\
\text { activity) }\end{array}$ & 6.4 & 52 & 0.26 & $15.5[4-35]$ & 216 [16-466] & $8.0[2.0-34.1]$ \\
\hline
\end{tabular}

Notice the very low duty-cycle of bouts UD in the spawning with no sneaking activity. $S=$ duration of the sneaking period (replicates $1-4$ ) or record length (replicate 5 ); $\Sigma U D=$ sum of durations of bouts UD; $\Sigma G A P=$ sum of durations of gaps UD.

${ }^{\text {a }}$ See Materials and methods for calculations 


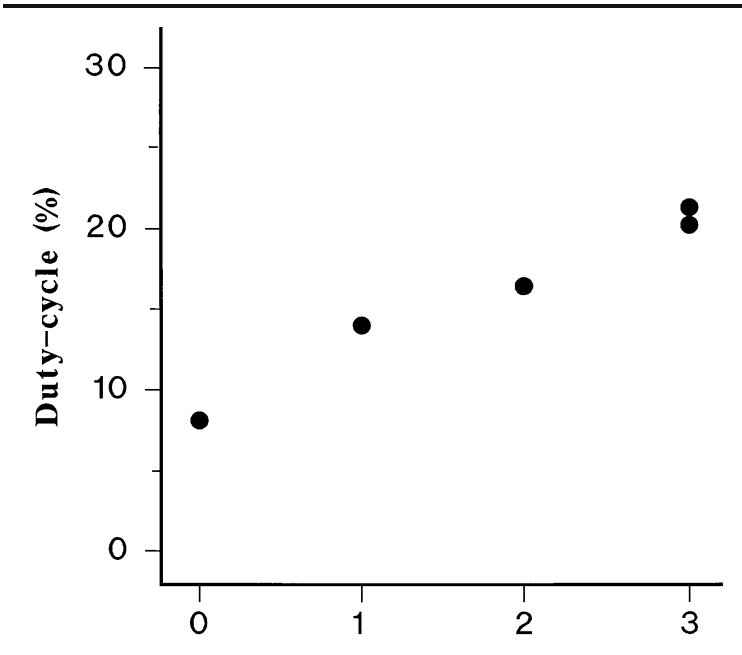

Number of sneak intrusions

Fig. 3 The relationship between the mean duty-cycle of bouts of upside-down by the large male and number of nest intrusions by the small male observed during the interaction $(n=5)$

Results of the MCPT tests showed the presence of (two) significant $(p<0.05)$ points of abrupt change in mean bout length only in one replicate (replicate 2): bouts UD between the two change points tended to be of shorter length than the other bouts of the sequence (Fig. 4). However, this intermediate sequence of short bouts did not follow immediately in the bout sequence the only sneak intrusion of the replicate.

By contrast, all the nine observed sneak intrusions, but one (see below), were followed by a temporary decrease of gap length. Accordingly, the duty-cycle increased from the baseline, at around $10 \%$, to a peak from $30 \%$ to $60 \%$ (Fig. 3, single $Y$-axis, top graphs). After 10-18 gaps (gray-colored segments on the cumulative gap length plots, Fig. 4) both the gap length and duty-cycle returned toward values typical of the period preceding the sneak intrusion. Notice in replicate 3 the only sneak intrusion not followed by any apparent change of gap length (and mean dutycycle) occurred toward the end of the sneaking period, i.e., well apart from the first two. Results of MCPT tests supported conclusions based on visual inspection of cumulative gap length plots. One, or two, significant $(p<0.05)$ change points on the cumulative gap length plots were found in all replicates with sneak intrusions (Fig. 3, replicates 14). The first change point was the gap subsequent (replicates 1, 2 and 3), or one very close (replicate 4), to the occurrence of the first nest intrusion by the parasitic male. The second change point (replicates 2,
3 and 4) was always a gap located at the end of a sequence of short gaps.

\section{Discussion}

The results of this study provide further behavioral support for the presence of two spawning tactics in the male population of the grass goby: the parasitic tactic adopted by small, young males, and the nest-holding tactic adopted by large, adult males (Mazzoldi et al. 2000; Scaggiante et al. 2005).

The presence of the parasitic male inside the nest chamber elicited aggressive sound emission and chasing behaviour by the nest-owner. These responses were followed by a marked increase of the spawning activity by the large male: the frequency of upsidedown movements (but not their mean length) augmented initially for $10-15 \mathrm{~min}$, then decreased to the levels typical of the period preceding the sneak intrusion, the whole cycle lasting 20-25 min. By contrast, the period of time the parasitic male stayed in the nest chamber (from 2 to $200 \mathrm{~s}$ ) varied remarkably also among different occurrences within the same spawning. Therefore, the spawning response shown by the nest-holding male to the sneak intrusion was apparently independent of the residence time of the parasitic male in the nest, suggesting the success of the grass goby parasitic male might well rely upon his ability to remain undetected inside the nest chamber. The occurrence of upside-down movements in the grass goby has been shown to be associated to genital papillae rubbing and sperm trails release (Ota et al. 1996). Thus, although we did not measure the amount of sperm released throughout the spawning quantitatively, the observed increase of frequency of upside-down movements during the response period could be indicative of higher number of sperm trails released during this period. If such is the case, the territorial male could increase the probability of own sperm to win in the "raffle" with that of the parasitic male, according with Parker's models (1990). This could be adaptive for the grass goby male, for the required extra-amount of sperm to cope with the sperm competition risk would be released only when the probability of egg fertilization by the parasitic male is highest. Scaggiante et al. (2005) showed an increase of intensity of aggressive behavior but no adjustment of sperm expenditure by the territorial 
(\#1)
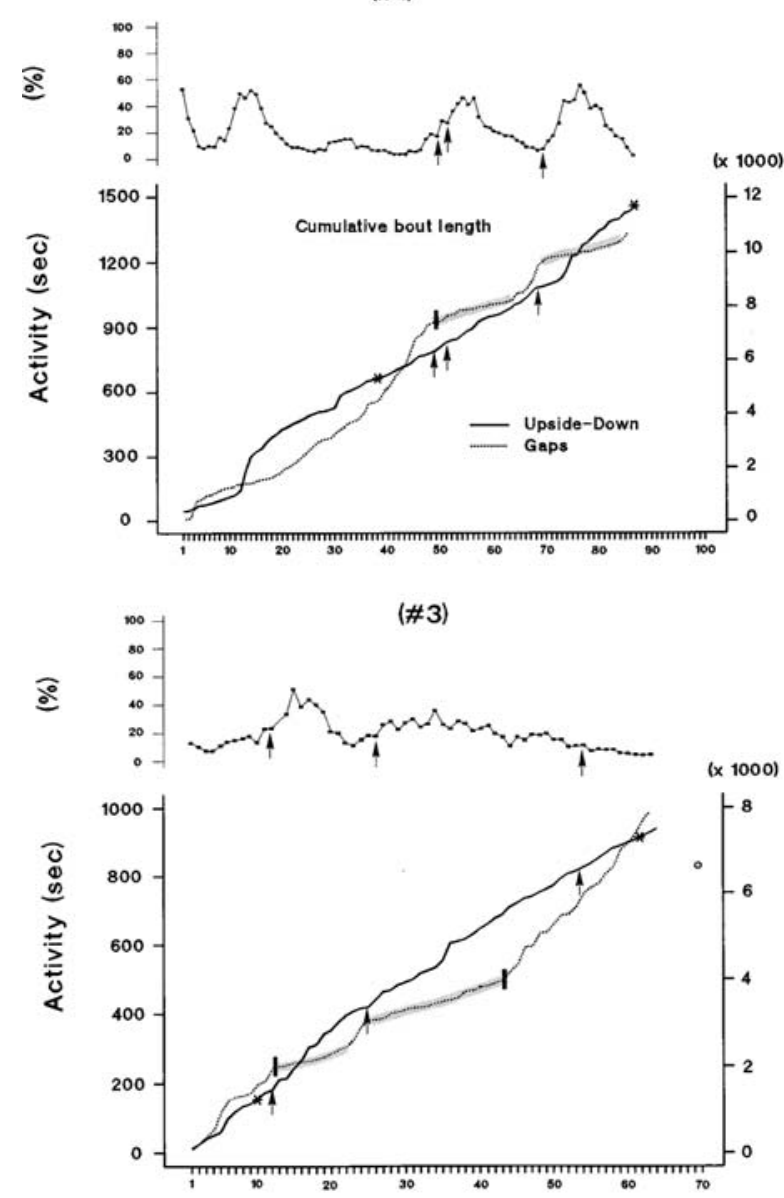

Sequence number of bout

Fig. 4 The cumulative length of bouts UD and gaps UD (main plots), and variation of the duty-cycle of UD (single $Y$-axis plots above the main plots), plotted against the sequence number of bout, in the four replicates with an active parasitic male (note that the term 'bout' is used both for the activity and for gaps). The sum of durations of bouts UD is reported on the left $Y$-axis of the main plot, whereas the sum of durations of gaps UD is reported on the right $Y$-axis. The plot of the duty-cycle was computed by averaging the values of the duty-cycle for two points on either side of a target value (method of the simple moving average, STATGRAPHICS statistical software package). The (averaged) value of the duty-cycle was then reported for each position of the bout ( $X$-axis on the main plot) used to calculate the target value. The use of a moderate level of smoothing of the curve for calculating the moving averages

grass-goby male exposed to increasing number of sneakers. While the first finding is consistent with our observations on the aggressive responses shown by the territorial male toward the sneaker, the lack of sperm-adjustment of the Scaggiante et al. (2005) study contrasts with the increase of the spawning
(\#2)
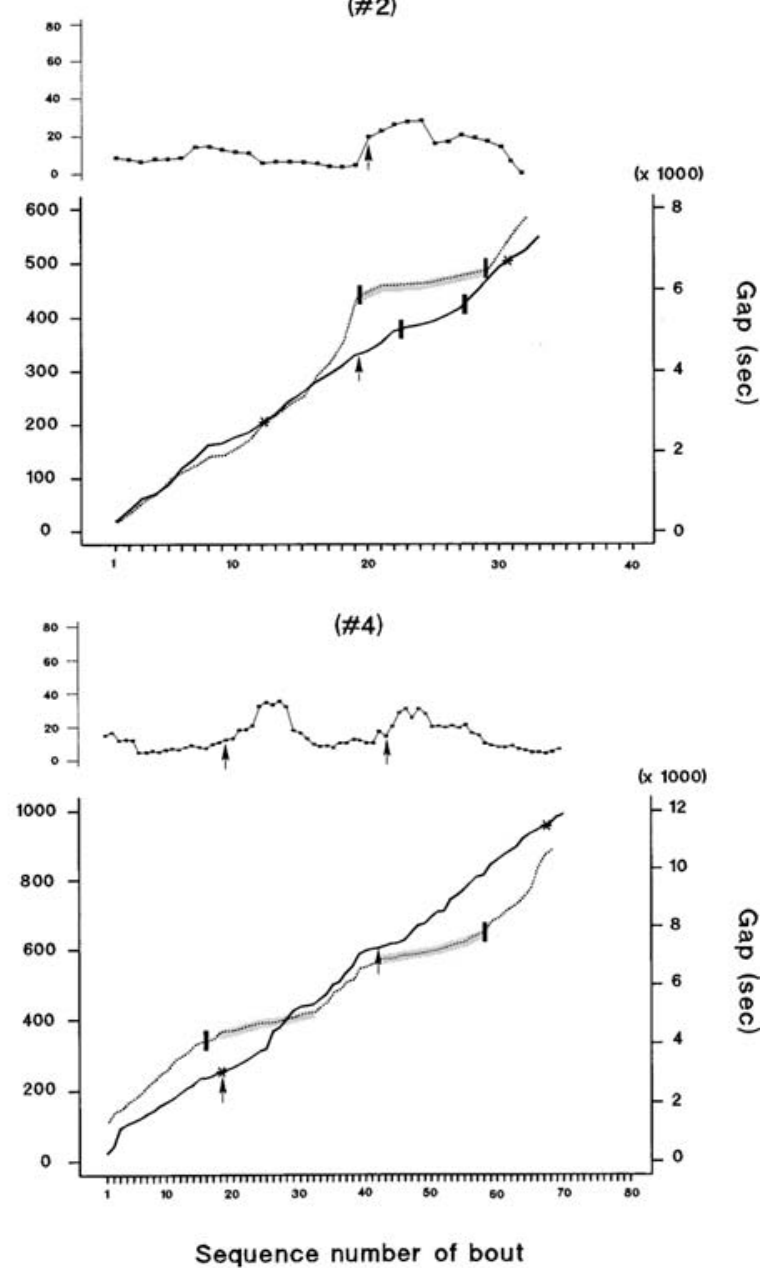

allowed a better representation of significant trends of the dutycycle of UD over time. Notice the duty-cycle was calculated for all bouts UD of the sequence, but the last one. The beginning and end of the sneaking period of each replicate is marked with an asterisk on the cumulative bout length plots of UD. Arrows on the cumulative plots of UD (and on the corresponding dutycycle curve) mark the position of sneak intrusions. For example, in replicate 2 a sneak intrusion occurred close to the 20th bout UD. Bars on the bout length plots indicate points of abrupt change in mean bout length, or mean gap length, as determined from the Multiple Change Point test (see Materials and methods for details). Note the decrease in mean gap length (gray-colored segments with lower slope on the cumulative bout length curve of gaps UD), and the peak in the duty-cycle curve, following a sneak intrusion. See text for further details

activity by the territorial male after a sneak-intrusion observed in the present study. This discrepancy can be easily explained, however, by the different experimental procedures of the two studies. Scaggiante et al. (2005) tested sperm competition by presenting the parental mare with sneakers confined behind a 
transparent partition, thereby preventing the free access of the sneakers to the nest of territorial male. Therefore, no nest intrusion by the sneaker occurred and, hence, no response by the territorial male in terms of increased spawning activity or sperm release was observed. In our study, the sneaker could interact freely with the territorial male inside the buried nest in the presence of a spawning female, a situation simulating the field conditions of spawning of this species. Our findings, therefore, draw the attention on the importance of testing the fish subjects within the appropriate environmental context for attaining reliable conclusions on the functional aspects of behavioral responses. Since we did not quantify sperm concentration in the water, the demonstration of the increased sperm output by the territorial grass-goby male after a sneak intrusion await further experimental work.

Acknowledgements This study was supported by M.U.R.S.T. $60 \%$.

\section{References}

Cole KS (1982) Male reproductive behavior and spawning success in a temperate zone goby (Coryphopterus nicholsi). Can J Zool 60:2309-2316

Fagen RM, Young DY (1978) Temporal patterns of behaviors: durations, intervals, latencies, and sequences. In: Colgan PW (ed) Quantitative ethology. Wiley, New York, pp 79-114

Haccou P, Meelis E (1992) Statistical analysis of behavioral data. Oxford University Press, Oxford

Kemadjou Nijwa JR, Muller P, Klein R (2004) Variations of sperm release in three batches of zebrafish. J Fish Biol $64: 475-482$
Magnhagen C (1992) Alternative reproductive behavior in the common goby (Pomatoschistus microps): an ontogenetic gradient. An Behav 44:182-184

Malavasi S, Lindström K, Sundström L (2001) Behavior and success of sneaker males in the sand goby, Pomatoschistus minutus. Acta Ethol 4:3-9

Malavasi S, Coppola J, Pranovi F, Granzotto A, Franco A, Torricelli P (2002) Habitat riproduttivo di Zosterisessor ophiocephalus Pall. (Pisces, Gobiidae) in laguna di Venezia e osservazioni sulle caratteristiche dei riproduttori. Lav Soc Ven Sc Nat 27:47-56

Marconato A, Rasotto MB, Mazzoldi C (1996) On the mechanism of sperm release in three gobiid fishes (Teleostei: Gobiidae). Environ Biol Fish 46:321-327

Mazzoldi C, Scaggiante M, Ambrosin E, Rasotto MB (2000) Mating system and alternative mating tactics in the grass goby (Zosterisessor ophiocephalus). Mar Biol 137:1041-1048

Ota D, Marchesan M, Ferrero EA (1996) Sperm release behavior and fertilization in the grass goby. J Fish Biol 49:246-256

Parker GA (1990) Sperm competition games: raffles and roles. Proc Royal Soc Lond B 242:121-126

Scaggiante M, Mazzoldi C, Petersen CW, Rasotto M (1999) Sperm competition and mode of fertilisation in the grass goby (Zosterisessorophiocephalus). J Exp Zool 283:81-90

Scaggiante M, Rasotto MB, Romualdi C, Pilastro A (2005) Territorial male gobies respond aggressively to sneakers but do not ad just their sperm expenditure. Behav Ecol 16:1001-1007

Siegel S, Castellan NJ (1992) Statistica non parametrica. McGraw-Hill, New York, p 477

Sokal RR, Rohlf FJ (1995) Biometry, 3rd edn. Freeman, New York, p 880

Stoltz JA, Neff BD (2006) Sperm competition in a fish with external fertilization: the contribution of sperm number, speed and length. J Evol Biol, 1873-1871

Torricelli P, Malavasi S, Novarini N, Pranovi F, Mainardi D (2000) Elongation of fin rays in parental males of Zosterisessor ophiocephalus. Environ Biol Fish 58:105108 